\title{
Концепция гуманитарной интервенции и действующее международное право
}

Шайымбетова Ж.К. ${ }^{*}$

Концепция гуманитарной интервенции является одной из основных проблем современного миропорядка. Речь идет о ее правовой необоснованности и спорной легитимности. Термин «гуманитарная интервенция» был введен западными странами для оправдания применения вооруженной силы против другого государства в целях защиты прав человека в этой стране вопреки воле его правительства. В данной статье под гуманитарной интервенцией понимается применение вооруженной силы одним или более государствами против другого государства с целью защиты прав населения на территории этого государства без его согласия.

В статье раскрывается понятие и содержание гуманитарной интервенции, проводится ее разграничение со смежными понятиями. Это необходимо в связи с тем, что концепция гуманитарной интервенции является доктринальной конструкцией, что нет общепризнанного международного документа, в котором давалось бы ее исчерпывающее понятие.

В статье обосновывается противоправность гуманитарной интервенции. Для того чтобы межгосударственное сотрудничество в области защиты прав человека в критических ситуациях развивалось в рамках современного действующего мирового порядка, необходимо применять международно-правовые механизмы.

Ключевые слова: гуманитарная интервенция; права человека; принцип неприменения силы; принцип невмешательства; государственный суверенитет.

Одной из своих главных целей Организация Объединенных Наций провозгласила «...поощрение и развитие уважения к правам человека и основным свободам для всех, без различия расы, пола, языка и религии» (п. 3 ст. 1 Устава ООН). В развитие данного положения было

\footnotetext{
* Шайымбетова Жылдыз Казбековна - аспирант кафедры международного права Дипломатической академии МИД России. jika16@yandex.ru.
} 
разработано и принято большое количество международных актов, которые создали правовую базу для защиты прав и свобод человека. Одновременно шел процесс создания международных органов, механизмов для контроля за выполнением государствами их международных обязательств в области защиты прав человека. Практика межгосударственных отношений внесла много нового в вопросы, касающиеся защиты прав человека. В частности, изменились положения о том, каковы границы действия принципа невмешательства в дела, входящие во внутреннюю компетенцию государств, когда совершаются нарушения прав человека. Если ранее регламентация правового положения граждан являлась внутренним делом государства, то теперь это также и международный вопрос - национальные нормы о правах человека должны соответствовать международным стандартам. Рассмотрение в международных организациях нарушений государством его обязательств, а также обращение участников договора к государству, не соблюдающему его положения, стало правомерным и не является вмешательством во внутренние дела. Это, бесспорно, положительная тенденция в развитии норм и принципов международного права, касающихся защиты прав человека.

Термин «гуманитарная интервенция» был введен западными странами и учеными для оправдания применения вооруженной силы против другого государства в целях защиты прав человека в этой стране, вопреки воле его правительства.

В качестве одного из определений гуманитарной интервенции в современных условиях можно привести выдержку из доклада, подготовленного двумя голландскими неправительственными организациями - Консультативным комитетом по правам человека и внешней политике и Консультативным комитетом по вопросам публичного международного права. В докладе гуманитарная интервенция определяется как угроза или использование силы «одним или более государствами в пределах территории другого государства с единственной целью остановить или предотвратить крупномасштабные, серьезные нарушения основных прав человека, которые имеют место или совершение которых в ближайшем будущем очевидно, независимо от гражданства, причем к таким правам в особенности относится право индивидов на жизнь в случаях, когда угроза или использование силы осуществляется без предварительного получения полномочий от компетентных 
органов ООН,либо без разрешения законного правительства страны, на территории которой интервенция имела место» ${ }^{1}$.

Термин «гуманитарная интервенция» является доктринальной конструкцией; нет общепризнанного международного документа, в котором давалось бы исчерпывающее понятие гуманитарной интервенции. Поэтому необходимо его разграничение со смежными понятиями.

В международной практике существуют примеры использования вооруженных сил на территории иностранных государств, имеющего гуманитарный характер, которые следует отличать от гуманитарной интервенции. Так, например, правомерно с точки зрения международного права иностранное вооруженное вмешательство на территории другого государства с согласия последнего.

Иногда термин «гуманитарная интервенциия применяется в случаях использования вооруженных сил одних государств на территории других с иелью зашиты или спасения собственных граждан. Так, профессор В.А. Карташкин отмечает, что «...нельзя допускать того, чтобы каждое государство самостоятельно решало вопрос о своем праве на гуманитарную интервенщию. Единственным исключением из этого общего правила могут быть силовые акиии для действительного спасения жизни своих граждан, находящихся на территории иностранного государства» ${ }^{2}$. Однако использование этого термина в подобных ситуачиях неоправданно. Некоторые ученье придерживаются той точки зрения, что такие действия предпринимаются на основании ст. 51 Устава ООН. Н.Б. Крылов отмечает, что вооруженныле действия по защите своих граждан, находящихся в опасности за пределами государства, являются формой самообороны согласно cт. 51 и признаются, пользуются поддержкой и применяются в меж-

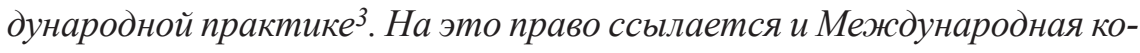
миссия по вопросам интервенции и государственного суверенитета

\footnotetext{
${ }^{1}$ The Use of Force for Humanitarian Purposes / Enforcement Action for Humanitarian Purposes and Humanitarian Intervention // Advisory Committee on Human Rights and Foreign Policy and Advisory Committee on Issues of Public International Law. Report No. 15. The Hague, 18 June. 1992. P. 4. Цитируется по: Черниченко С.В. Теория международного права. Т. 2: Старые и новые теоретические проблемы. М., 1999. С. 472.

2 Карташкин В.А. Гуманитарная интервенция в глобализирующемся мире // Юристмеждународник. 2003. № 3. С. 6.

${ }^{3}$ См.: Крылов Н.Б. Защита сограждан, находящихся в опасности за рубежом // Международная жизнь. 1995. № 1. С. 124-130.
} 
(неправительственный орган), созданная при поддержке правительства Канадьл. В ее докладе, опубликованном в 2001 г. под названием "Ответственность за зашиту», отмечается, что «ссылки на гуманитарную интервенцию при защите государством своих граждан, находящихся за рубежом, неоправданны, поскольку такая ситуачия подпадает под ст. 51 Устава ООН о праве на самооборону»4. В то же время отмечается, что для действий на основании ст. 51 необходимо вооруженное нападение на государство, а значит, такие действия следует рассматривать как вооруженные самозащитные меры (меры самопомощи, отличные от индивидуальной самообороны). Они отличаются от самооборонь тем, что основанием для них является не вооруженное нападение, а посягательства на безопасность государства менее серьезного характера 5 . В любом случае эти действия не являются гуманитарной интервениией, поскольку они не направлены на защиту от правительства иностранного государства людей независимо от их гражданства.

Наблюдается тенденция (главным образом в западной доктрине) в защиту концепции гуманитарной интервенции выдвигать тезис о том, что якобы принцип уважения прав человека имеет приоритет перед всеми другими принципами международного права ${ }^{6}$. В частности, авторы упомянутого доклада (Консультативного комитета по правам человека и внешней политике и Консультативного комитета по вопросам публичного международного права) оправдывают допустимость гуманитарной интервенции ссылками на возрастающее значение обязательства защищать и поощрять на международном уровне права человека, которое якобы ограничивает сферу применения п. 7 ст. 2 Устава ООН (принципа невмешательства) ${ }^{7}$. Высказывается мнение, что в современном международном праве принципы суверенитета и невмешательс-

${ }^{4}$ The Responsibility to Protect. Report of the International Commission on Intervention and State Sovereignty. December 2001. Ottawa: International Development Research Centre, 2001. P. 34.

${ }^{5}$ См.: Черниченко С.В. Теория международного права. Т. 2: Старые и новые теоретические проблемы. М., 1999. С. 464-475.

${ }^{6}$ Hoffmann S. The Politics and Ethics of Military Intervention // Survival. 1996. Vol. 37, № 4. P. 35.

7 The Use of Force for Humanitarian Purposes/ Enforcement Action for Humanitarian Purposes and Humanitarian Intervention // Advisory Committee on Human Rights and Foreign Policy and Advisory Committee on Issues of Public International Law. Report No. 15. The Hague, 18 June. 1992. P. 8. 
тва во внутренние дела ограничиваются правами человека ${ }^{8}$. Однако это не говорит о том, что нужно пересматривать основные принципы международного права, в том числе принцип невмешательства, и понятие государственного суверенитета.

Не следует забывать, что в основополагающих международно-правовых документах, таких как Декларация о принципах международного права, касающихся дружественных отношений и сотрудничества между государствами в соответствии с Уставом ООН 1970 г., Заключительный акт СБСЕ 1975 г., указано, что все основные принципы международного права «являются взаимозависимыми и каждый принцип должен рассматриваться в контексте всех других принципов» ${ }^{9}$. Следует подчеркнуть, что, хотя Декларация принципов по своей юридической природе представляет собой рекомендацию, однако, поскольку она была принята Генеральной Ассамблеей без голосования, ее можно считать официальным толкованием основных принципов международного права, данным ООН. Декларация раскрывает содержание принципов международного права. Они сформулированы применительно не только к членам ООН, но и вообще ко всем государствам. Надо добавить, что Заключительный акт Совещания по безопасности и сотрудничеству в Европе, подписанный в Хельсинки 1 августа 1975 г, начинается с Декларации 1970 г., и содержит принципы, которыми государства-участники будут руководствоваться во взаимных отношениях. В Заключительном акте также подчеркивается взаимосвязанность закрепленных в нем принципов. В нем говорится: «Все принципы, изложенные выше, имеют первостепенную важность, и, следовательно, они будут одинаково и неукоснительно применяться при интерпретации каждого из них с учетом других» ${ }^{10}$.

Принципы международного права - общепризнанные и наиболее важные нормы международного права, составляющие основу межгосударственных отношений. Они носят императивный характер, то есть подразумевается недопустимость отступления от них путем заключения договора между теми или иными государствами. Отменить эти принципы можно лишь с общего согласия членов международного сообщества, а не какой-либо группы государств. Принцип невмешатель-

\footnotetext{
8 Карташкин В.А. Гуманитарная интервенция в глобализирующемся мире // Юристмеждународник. 2003. № 3. С. 5.

9 Док. ООН A/RES/2625 (XXV).

10 Действующее международное право. М., 2002. Т. 1 С. 47.
} 
ства - один из этих принципов. Следует отметить, что граница между делами, входящими во внутреннюю компетенцию государств, и международными исторически подвижна. То, что раньше относили к внутренней компетенции государств, в настоящее время в ряде случаев уже в нее не входит или входит лишь частично. Более того, какие-либо государства могут заключить между собой договор, по которому в своих взаимоотношениях они обязуются те или иные вопросы, традиционно считающиеся входящими во внутреннюю компетенцию государств, не считать таковыми. Однако сделать это они вправе лишь в отношении друг друга, а не третьих государств, и такой договор не должен отразиться на общепризнанном содержании принципа невмешательства. Как отмечает С.В. Черниченко, «если вопрос об отмене или пересмотре принципа невмешательства ставится для того, чтобы создать условия, позволяющие беспрепятственно выражать на межгосударственном уровне озабоченность по поводу нарушений прав человека в какой-либо стране или их осуждение, то сама его постановка неверна» ${ }^{11}$. В последние годы в мировом сообществе признается, что обсуждение нарушений прав человека в конкретных странах или попытки начать такое обсуждение, принятие каких-либо резолюций по этим вопросам не рассматриваются более как противоречащие принципу невмешательства. Для акций подобного рода отменять или изменять этот принцип или пересматривать понятие государственного суверенитета не требуется. В современных условиях государства, являющиеся объектом критики по поводу нарушений прав человека, предпочитают не ссылаться на принцип невмешательства, а давать объяснения по существу.

Если речь идет об отмене или изменении принципа невмешательства с целью легализовать возможность вооруженного вмешательства для защиты прав человека без санкции Совета Безопасности, тогда придется отменять или изменять и другие принципы международного права и, кроме того, радикально пересматривать Устав ООН. В первую очередь это относится к принципам суверенного равенства государств и неприменения силы, которые закреплены в Уставе ООН.

Следует отметить, что ООН создавалась как организация, направленная прежде всего на укрепление международного мира и безопасности путем защиты территориальной целостности, политической независимости и суверенитета государств-членов. Однако в настоящее

11 Черниченко С.В. Операция НАТО в Югославии и международное право // Международная жизнь. 1999. № 11. С. 105. 
время нарушения прав человека чаще всего носят внутригосударственный характер, а большая часть вооруженных конфликтов являются внутренними (немеждународного характера). Это поставило Организацию перед трудностью: как совместить принцип суверенитета государств-членов с миссией по защите прав человека в этих государствах ${ }^{12}$.

Государственный суверенитет - это верховенство государства в пределах его границ и независимость в межгосударственных отношениях.

В настоящее время в связи с новыми угрозами и вызовами постоянно обсуждаются вопросы о необходимости пересмотра содержания государственного суверенитета ${ }^{13}$. В политических работах, а также главным образом в зарубежных международно-правовых исследованиях говорят о принципиальной возможности ограничения государственного суверенитета. Как правило, этот вопрос ставят в связи с обсуждением допустимости гуманитарных интервенций. В сущности, гуманитарная интервенция как предпринимаемое в одностороннем порядке без санкции Совета Безопасности ООН каким-либо государством или группой государств вооруженное вмешательство с целью пресечения нарушений прав человека, совершаемых властями определенного государства в отношении собственного населения, - нарушение принципа неприменения силы, закрепленного в Уставе ООН, и суверенитета государства. «В настоящее время суверенитет как качественная категория носит абсолютный характер. Государственный суверенитет не имеет границ, он неделим, представляя собой единую волю народа - он либо есть, либо его нет» ${ }^{14}$. Поэтому суверенитет указанного государства не может считаться ограниченным в результате упомянутого вмешательства, поскольку он является юридическим качеством государства. Это именно качественная, а не количественная характеристика, и по этой причине не приходится говорить об ограничении государственного суверенитета ${ }^{15}$.

12 CM.: The Responsibility to Protect. Report of the International Commission on Intervention and State Sovereignty. December 2001. Ottawa: International Development Research Centre, 2001. P. 13.

13 См. напр., Кузнецова Е. Суверенитет. Незыблемый и неделимый. Суверенитет государства может быть ограничен, если оно им злоупотребляет// Международная жизнь. 2004. № 7-8. С. 151-155; Поликанов Д. Концепция «принуждения к миру»: теория и практика// Азия и Африка сегодня. 2004. № 10. С. 67-69.

14 Моисеев А.А. Суверенитет государства в современном мире. Международно-правовые аспекты. М.: Научная книга, 2006. С. 37.

15 См.: Черниченко С.В. Правовые аспекты соотношения государственного суверенитета и противодействия новым угрозам и вызовам // Актуальные международно-правовые 
Государственный суверенитет до сих пор является краеугольным камнем международно-правового правопорядка, однако постепенно классическое понимание суверенитета сталкивается с пониманием того, что, нарушая права человека, государства злоупотребляют своими суверенными правами, а потому на такие нарушения должно реагировать международное сообщество. Поскольку обязанность уважать права человека является обязательством erga omnes, массовые и грубые нарушения прав человека в каком-либо государстве необходимо рассматривать как нарушение в отношении международного сообщества в целом. Как отмечает В.А. Карташкин, «в данном контексте усилия, предпринимаемые мировым сообществом, отдельными государствами и направленные на соблюдение фундаментальных прав и свобод в глобальном масштабе, не могут рассматриваться как вмешательство во внутренние дела» ${ }^{16}$. Таким образом, вопрос заключается в том, какие методы допустимы в отношении реагирования на указанные нарушения.

Концепция гуманитарной интервенции наряду с вопросами защиты прав человека сопряжена с таким аспектом международного права, как применение вооруженной силы в международных отношениях.

На протяжении всей истории человечества война рассматривалась как законное средство осуществления внешней политики и разрешения международных разногласий и конфликтов. Однако с начала XX века постепенно начался процесс ограничения применения силы. Большое значение в этом отношении сыграло международное гуманитарное право, которое следует связывать как с договорными, так и с обычно-правовыми нормами. Но, как известно, эти нормы основывались на принципе jus ad bellum, были направлены главным образом на достижение соглашений, которые регулировали бы правила ведения военных действий, а также уменьшение бедствий войны, но не на исключение применения вооруженной силы. Устав Лиги Наций частично ограничил право государств «прибегать к войне», а Пакт Бриана-Келлога 1928 г. лишь осудил «обращение к войне для урегулирования международных споров». Государства-участники отказались во взаимных отношениях от войны «в качестве орудия национальной политики».

и гуманитарные проблемы // Сборник статей. Вып. VI / ДА МИД России. М., 2005. C. $230-234$.

16 Карташкин В.А. Гуманитарная интервенция в глобализирующемся мире // Юристмеждународник. 2003. № 3. С. 5. 
Положение изменилось с принятием Устава ООН. Одна из фундаментальных международно-правовых норм межгосударственных отношений заключается в отказе от применения силы, закрепленном в п. 4 ст. 2 Устава ООН, запрещающей любую угрозу силой или ее применения «как против территориальной неприкосновенности или политической независимости любого государства, так и каким-либо другим образом, несовместимым с Целями Объединенных Наций».

Данная норма Устава носит императивный характер. Высказана точка зрения, согласно которой в современном международном праве не существует принципа неприменения силы, поскольку «в п. 4 ст. 2 Устава ООН (...) говорится всего лишь о воздержании от применения силы или угрозы применения насилия» ${ }^{17}$ и указывается, таким образом, на диспозитивность этого принципа. Профессор Ю.Н. Малеев считает, что «в реальных условиях действует принцип адекватного и пропорционального применения силы» ${ }^{18}$. Представляется, что подобное толкование п. 4 ст. 2 Устава ООН является не слишком убедительным.

Во-первых, следует обратить внимание на то, что в английском тексте Устава ООН употребляется выражение shall refrain from...; в юридических текстах глагол shall в третьем лице обозначает долженствование.

Еще одним доводом против упомянутого толкования п. 4 ст. 2 Устава ООН является то, что впоследствии был принят ряд документов, конкретизирующих принцип запрещения угрозы силой или ее применения. Среди указанных документов - Декларация о принципах международного права 1970 г., где в названии принципа также используется слово «воздерживаться», однако далее в Декларации указывается, что угроза силой или ее применение как против территориальной целостности или политической независимости любого государства, так и каким-либо другим образом, несовместимым с целями ООН, является нарушением международного права и Устава ООН. В Декларации подчеркивается: сила или угроза силой «никогда не должны применяться в качестве средства урегулирования международных вопросов» ${ }^{19}$. Другим важным документом является Декларация об усилении эффективности принципа отказа от угрозы силой или ее применения

17 Малеев Ю.Н. Реабилитация адекватного и пропорционального применения силы // Московский журнал международного права. 2004. № 3. С. 37.

18 Там же. С. 38.

19 Док. ООН А/RES/2625 (XXV), приложение П. 1. 
в международных отношениях ${ }^{20}$. Между тем, по мнению Ю.Н. Малеева, «само название Декларации некорректно», поскольку, с его точки зрения, такого принципа не существует ${ }^{21}$. Трудно согласиться с таким утверждением. Резолюции Генеральной Ассамблеи имеют большое значение при толковании той или иной нормы международного права. Они «представляют собой авторитетные свидетельства того, что считается правом и как оно понимается большинством государств» 22 . В данном случае можно предположить, что большинство государств понимает рассматриваемый принцип международного права именно так, как он сформулирован в названии Декларации. Учитывая, что Декларация была принята без голосования, она представляет собой, по сути, авторитетное толкование п. 4 ст. 2 Устава ООН, данное Генеральной Ассамблеей $\mathrm{OOH}$.

Таким образом, очевидно, что не имеет смысла переиначивать формулировку Устава ООН и конструировать несуществующий принцип. Если следовать подобной концепции, то оказывается, что главное в межгосударственных отношениях не то, что государства должны отказаться от применения силы, а, напротив, что должны применять ее. Это не соответствует современной тенденции развития мирового сообщества, когда оно отказалось от использования силы.

В настоящее время государство имеет право применять вооруженную силу исключительно в целях самообороны (ст. 51 Устава ООН) или по решению Совета Безопасности ООН. «Поэтому государства могут воздействовать на державу, нарушающую свои международные обязательства в области прав человека, лишь политическими, дипломатическими и иными средствами, но не при помощи вооруженной силы» 23 . Ее имеет право применять только Совет Безопасности ООН. Если нарушения прав человека достигают масштаба, угрожающего человечеству (а на межгосударственном уровне это означает угрозу международному миру и безопасности), тогда Совет Безопасности, установив существование такой угрозы, в соответствии с главой VII Устава $\mathrm{OOH}$ уполномочен принять решение о применении принудительных мер, в том числе и вооруженной силы. По такому пути и развивается

20 Док. ООН А/RES/42/22, приложение П. 3.

21 Малеев Ю.Н. Указ. соч. С. 38.

22 Лукашук И.И., Лукашук О.И. Толкование норм международного права. M.: Nota Bene, 2002.

${ }^{23}$ Хлестов О.Н. Гуманитарная интервенция: политические и международно-правовые аспекты // Юрист-международник. 2005. № 3. С. 37. 
международное сотрудничество для защиты прав человека в критических ситуациях, и Совет Безопасности ООН должен действовать в этих случаях более эффективно.

Возникает вопрос о том, как действовать в том случае, если резолюция о применении вооруженной силы будет заблокирована в Coвете Безопасности в результате использования права вето кем-либо из постоянных членов Совета. Ведь именно этот аргумент часто приводится в качестве обоснования ««права» отдельных государств брать на себя инициативу и проводить силовые операции против другого государства в случае неспособности Совета Безопасности принять решение с целью остановить происходящую на его территории гуманитарную катастрофу.

Действительно, если происходят массовые и грубые нарушения прав человека в каком-либо государстве и есть основания считать, что его власти причастны к их совершению, а Совет Безопасности изза применения кем-либо из его постоянных членов права вето не в состоянии предпринять принудительных действий с целью их пресечения, ООН оказывается не на высоте положения. Однако это не может свидетельствовать о том, что принцип единогласия постоянных членов Совета Безопасности устарел. В этой связи следует привести выдержку из работы Н.А. Ушакова, опубликованной еще в 1956 г., касающуюся принципа единогласия в ООН. «В основе принципа единогласия лежит также тот политический факт, что в современных международных отношениях пяти державам - СССР, Китаю, США, Великобритании и Франции - принадлежит ведущая роль и что от их сотрудничества и согласованности их действий главным образом зависит обеспечение и укрепление мира и международной безопасности» 24 . Это положение не менее актуально и в настоящее время.

Более того, когда Совет Безопасности не принимает никакого решения в результате, например, вето, то вовсе не доказано, что он не выполняет своих функций по какому-либо делу, так как он функционирует таким образом согласно Уставу $\mathrm{OOH}^{25}$.

Невозможность принятия решения Советом о применении мер военного характера из-за различия взглядов своих постоянных членов не означает, что любое государство или группа государств вправе

24 Ушаков Н.А. Принцип единогласия великих держав в Организации Объединенных Наций. М., 1956. С. 40.

25 Там же. С. 112. 
самостоятельно начать военные действия против другого государства, считая, что там совершаются тяжкие нарушения прав человека. Это будет нарушением принципа неприменения силы.

Еще один аргумент, выдвигаемый с целью обосновать соответствие гуманитарной интервенции международному праву, сводится к тому, что ст. 24 Устава ООН возлагает на Совет Безопасности лишь «главную ответственность за поддержание международного мира и безопасности». А потому в тех случаях, когда Совет Безопасности оказывается неспособным выполнить свои обязанности в соответствии со ст. 24 и главой VII Устава ОOH, на государства-члены возложена субсидиарная ответственность. Однако ст. 24, возлагая на Совет Безопасности основную ответственность за поддержание международной безопасности, как будто бы говорит о субсидиарной ответственности Генеральной Ассамблеи, а не государств - членов ООН. Такое толкование якобы подтверждается принятой в 1950 г. резолюцией «Единство в пользу мира» 26 , в которой Генеральная Ассамблея заявила о том, что она несет субсидиарную ответственность, если Совет Безопасности оказывается неспособным выполнить свои обязанности. Согласно п. 1 резолюции, «если Совет Безопасности, в результате разногласия его постоянных членов, оказывается не в состоянии выполнить свою главную обязанность по поддержанию международного мира и безопасности во всех случаях, когда имеются основания усматривать угрозу миру, нарушение мира или акт агрессии, Генеральная Ассамблея немедленно рассматривает этот вопрос с целью сделать членам Организации необходимые рекомендации относительно коллективных мер, включая - в случае нарушения мира или акта агрессии - применение, когда это необходимо, вооруженных сил для поддержания или восстановления международного мира и безопасности».

Следует отметить, что в свое время данная резолюция была принята в нарушение Устава ООН ${ }^{27}$. В годы преобладания прозападного большинства в Генеральной Ассамблее резолюция активно поддерживалась, однако в настоящее время, в связи с изменением соотношения сил, отношение к ней стало характеризоваться сдержанностью ${ }^{28}$. Тем

26 Док. ОOH A/RES/377 (V).

27 См. подробнее: Ушаков Н.А. Принцип единогласия великих держав в Организации Объединенных Наций. М., 1956. С. 110-114; Федоров В.Н. ООН и проблемы войны и мира. М.: Международные отношения, 1988. С. 72-74.

${ }^{28}$ Федоров В.Н. ООН и проблемы войны и мира. М.: Международные отношения, 1988. C. 73. 
не менее эта резолюция может служить для того, чтобы показать несостоятельность утверждений о том, что государства - члены ООН несут субсидиарную ответственность за поддержание международного мира и безопасности.

Нередко утверждается, что гуманитарная интервенция допустима с санкции Совета Безопасности ${ }^{29}$. Эта точка зрения получила определенную поддержку в доктрине. Например, в сборнике статей российских и американских авторов, подготовленном совместно специалистами в области международного права, имеются следующие высказывания: «...следует разработать критерии правомерности гуманитарной интервенции, санкционированной ООН» 30 ; «Гуманитарная интервенция, которая проводится без санкции Совета Безопасности $\mathrm{OOH}$, противоречит основным принципам современного международного права» ${ }^{31}$. Также в этой связи обращает на себя внимание доклад уже упомянутой Международной комиссии по вопросам интервенции и государственного суверенитета, которая «выступает за то, что любая гуманитарная интервенция может быть осуществлена лишь с санкции Совета Безопасности ООН» ${ }^{32}$.

Однако вряд ли целесообразно в данном случае применять термин «гуманитарная интервенция». Во-первых, потому, что поводом к такой интервенции (если следовать букве Устава ООН) являются не нарушения прав человека как таковые, а угроза международному миру и безопасности, возникшая в результате нарушения этих прав. Во-вторых, под этим термином в литературе, как правило, понимаются действия государств, осуществляемые без санкции Совета Безопасности ООН. Поэтому если бы Совет Безопасности принял решение о применении вооруженной силы для предотвращения или прекращения нарушений прав человека, поскольку они создают угрозу международному миру и безопасности, ее применение можно было бы назвать превентивными или принудительными мерами (действиями), предусмотренными рядом статей Устава ООН (ст. 5, 42, 50), а не правомерной гуманитар-

\footnotetext{
${ }^{29}$ См.: Макфарлейн Нил С. Многосторонние интервенции после распада биполярности // Международные процессы. 2003. № 1. С. 42.

${ }^{30}$ Вне конфронтации. Международное право в период после «холодной войны»: Сборник статей. М.: Спарк, 1996. С. 145.

${ }^{31}$ Неліп М.I, Мережко О.О. Силовий захист прав людини. Киів, 1998. С. 116.

${ }^{32}$ The Responsibility to Protect. December 2001. Report of the International Commission on Intervention and State Sovereignty.
} 
ной интервенцией ${ }^{33}$. Таким образом, признание Советом Безопасности ООН, что грубейшее нарушение прав человека создает угрозу миру, имеет важное значение.

В некоторых случаях предпринимаются попытки противопоставить правомерность и легитимность гуманитарной интервенции. Так, авторы доклада Института международных дел Дании правительству этого государства, признавая несоответствие гуманитарной интервенции, осуществляемой без одобрения Советом Безопасности ООН, действующему международному праву, указывают, что, тем не менее, она может быть легитимной с политической точки зрения. В Докладе указывается на асимметрию между существующими средствами принуждения и возможностями для нарушения норм международного права, в частности - норм, закрепляющих права человека: «Нарушители норм, закрепляющих права человека, защищены высокими стандартами государственного суверенитета и неприменения силы, в то же время применение принудительных мер против них зависит от политических органов и условий» ${ }^{34}$.

Представляется, что такой нигилистический подход к международному праву, по сути, оправдывающий его нарушение, является необоснованным. Во-первых, потому, что существуют определенные международно-правовые механизмы для пресечения нарушений прав человека. Во-вторых, даже в случае легализации гуманитарной интервенции она все равно не будет осуществляться во всех без исключения случаях нарушений прав человека, а значит и далее применение силы будет избирательным и будет зависеть от политических решений. К тому же, «возникновение универсальных норм, узаконивающих интервенцию, в значительной мере раздвинуло бы границы исключительных ситуаций и, таким образом, ослабило бы принцип невмешательства» ${ }^{35}$. В-третьих, для изменения норм международного права существуют соответствующие правовые механизмы, которые и должны применяться.

33 Черниченко С.В. Гуманитарная интервенция: международная противоправность // Актуальные международно-правовые и гуманитарные проблемы: Сборник статей. ДА МИД России. Вып. II. М.,, 2001. С. 141-142.

${ }^{34}$ См.: Humanitarian Intervention: Legal and Political Aspects. Copenhagen: Danish Institute of International Affairs, 1999. P. 23--25.

35 Макфарлейн Нил С. Многосторонние интервенции после распада биполярности // Международные процессы. 2003. № 1. С. 40. 
Таким образом, гуманитарная интервенция - это грубейшее нарушение международного права. Задача состоит в том, чтобы использовать международно-правовые механизмы, а также совершенствовать их, но не наделять отдельные государства правом применять вооруженную силу вопреки Уставу ООН. Как отмечает профессор О.Н. Хлестов, признание Советом Безопасности ООН, что грубейшее нарушение прав человека создает угрозу миру, имеет важное значение. Это означает, что в подобных ситуациях Совет Безопасности в соответствии с главой VII Устава ООН обязан применять принудительные меры, в том числе и вооруженную силу. По этому пути и развивается международное сотрудничество для защиты прав человека в критических ситуациях. Доказательством являются решения Совета Безопасности ООН: резолюция 1564 от 18 сентября 2004 г. по Судану, в которой сказано: «Положение в Судане представляет собой угрозу для международного мира и безопасности и стабильности в регионе». Аналогичные формулировки содержатся в резолюции 1542 от 30 апреля 2004 г. по Гаити, в резолюции 1572 от 15 ноября 2004 г. по Кот-д’Ивуар ${ }^{36}$.

\section{Библиографический список}

Вне конфронтации. Международное право в период после «холодной войны»: Сборник статей. М.: Спарк, 1996.

Действующее международное право. М., 2002. Т. 1.

Карташкин В.А. Гуманитарная интервенция в глобализирующемся мире // Юрист-международник. 2003. № 3.

Крылов Н.Б. Защита сограждан, находящихся в опасности за рубежом // Международная жизнь. 1995. № 1.

Кузнецова Е. Суверенитет. Незыблемый и неделимый. Суверенитет государства может быть ограничен, если оно им злоупотребляет // Международная жизнь. 2004. № 7-8.

Лукашук И.И., Лукашук О.И. Толкование норм международного права. М.: Nota Bene, 2002.

Макфарлейн Нил С. Многосторонние интервенции после распада биполярности // Международные процессы. 2003. № 1.

Малеев Ю.Н. Реабилитация адекватного и пропорционального применения силы // Московский журнал международного права. 2004. № 3.

${ }^{36}$ Хлестов О.Н. Понятие гуманитарной интервенции // Поддержка ООН. Сила права. 2005. Бюллетень № 3. С. 16. 
Моисеев А.А. Суверенитет государства в современном мире. Международно-правовые аспекты. М.: Научная книга, 2006.

Поликанов Д. Концепция «принуждения к миру»: теория и практика // Азия и Африка сегодня. 2004. № 10.

Ушаков Н.А. Принцип единогласия великих держав в Организации Объединенных Наций. М., 1956.

Федоров В.Н. ООН и проблемы войны и мира. М.: Международные отношения, 1988.

Хлестов О.Н. Гуманитарная интервенция: политические и международно-правовые аспекты // Юрист-международник. 2005. № 3.

Хлестов О.Н. Понятие гуманитарной интервенции // Поддержка ООН. Сила права. 2005. Бюллетень № 3.

Черниченко С.В. Гуманитарная интервенция: международная противоправность // Актуальные международно-правовые и гуманитарные проблемы: Сборник статей. ДА МИД России. Вып. II. М., 2001.

Черниченко С.В. Операция НАТО в Югославии и международное право // Международная жизнь. 1999. № 11.

Черниченко С.В. Правовые аспекты соотношения государственного суверенитета и противодействия новым угрозам и вызовам // Актуальные международно-правовые и гуманитарные проблемы: Сборник статей. ДА МИД России. Вып. VI. М., 2005.

Черниченко С.В. Теория международного права. Т. 2: Старые и новые теоретические проблемы. М., 1999.

Неліп М.I, Мережко О.О. Силовий захист прав людини. Киів, 1998.

Hoffmann S. The Politics and Ethics of Military Intervention // Survival. 1996. Vol. 37, № 4.

Humanitarian Intervention: Legal and Political Aspects. Copenhagen: Danish Institute of International Affairs, 1999.

The Responsibility to Protect. Report of the International Commission on Intervention and State Sovereignty. December 2001. Ottawa: International Development Research Centre, 2001.

The Use of Force for Humanitarian Purposes/ Enforcement Action for Humanitarian Purposes and Humanitarian Intervention// Advisory Committee on Human Rights and Foreign Policy and Advisory Committee on Issues of Public International Law. Report No. 15. The Hague, 18 June. 1992. 


\section{The Concept of Humanitarian Intervention and Applicable International Law (Summary)}

Jyldyz K. Shaiymbetova*

The concept of humanitarian intervention is one of the main problems of contemporary world order. The point is that the humanitarian intervention is legally inconsistent. The term "humanitarian intervention" was brought into service by western states and scientists to justify the use of military force against other state for human rights protection in this state, against will of its government.

Humanitarian intervention may be defined as the use of force by one or more states against another state with the aim of protection of human rights - citizens of this state that is human rights protection within the territory of another state without either the permission of its legitimate government or the authorization of the UN Security Council.

The article considers the content of humanitarian intervention, as well as its differentiation from the closely-related concepts. It is necessary because of the term "humanitarian intervention" is doctrinal construction; there is no acknowledged international instrument which gives a definition of this term.

The conclusion of the article is to show the illegality of humanitarian intervention. The task is that international cooperation for the human rights protection in crisis situations develops within contemporary applicable international law.

Keywords: humanitarian intervention; human rights; non-use of force; the principle of non-intervention; state sovereignty.

* Jyldyz K. Shaiymbetova - post-graduate student of the Chair of International Law, Diplomatic Academy MFA Russia. jika16@yandex.ru. 